\title{
STUDENTS PERSPECTIVES ON CHALLENGES WITHIN MULTI-DIVERSE DESIGN TEAMS
}

\author{
Bas FLIPSEN, Stefan PERSAUD and Reka MAGYARI \\ Delft University of Technology, Industrial Design Engineering
}

\begin{abstract}
In the IPD Master's in Industrial Design Engineering (TU Delft) we see a growing diversity of students. We see the international student population growing, but also see significant differences in prior education, socio-emotional aspects, and competences. Within the Advanced Embodiment Design (AED) course, students work in teams on a client-based design project for a full semester. In 2018-2019, 22 student-teams started out their endeavour, coached by eight coaches. On a weekly basis the coaches tracked the teams' performances by means of six key performance indicators. The weekly logs are aggregated, converted, and visualized in a performance dashboard which was used to lead the discussion on troublesome teams and solutions to get them back-on-track. In this cohort four fields were found: (i) cultural differences; (ii) differences in design approaches; (iii) emotional differences; and (iv) differences in student competences. These typical problems were the result of our own coaches' perspective, and not so much from a student's perspective. To really get a grip on team dynamics and issues involved, we wanted to know what students come across when functioning in a multi-diverse team. In this paper we present our exploration from students' perspective by evaluating the end-of-course reflections. The goal of this research is to learn about the most occurring issues within multi-diverse teams and come to applicable solutions to help teams during the project. We started out with a word cloud to find the most common terms and use those as labels for clustering. 308 unique students' quotations were labelled and clustered into three main clusters based on project management, emotional interaction and interdisciplinary, and 11 subclusters. The clustered data revealed interesting results in terms of (sub)clusters as well as their relationships to each other. Visualizing the associations between the subclusters show for example that lack of clear consensus on leadership causes challenges from various aspects leading to difficulties in role agreements, task concerns and design approaches, as well as managing individual behaviours. Despite initial assumptions, Cultural Differences led to the smallest number of challenges but scored high in terms of relations with other clusters. In this paper we will present our findings on the issues clustered and the prioritization of importance. We will discuss the relationships between the clustered student challenges, and review solutions which can help them out in becoming highly performing teams.
\end{abstract}

Keywords: Multi-diverse, teams, lessons learned, reflection, team dynamics

\section{INTRODUCTION}

In the IPD Master at Industrial Design Engineering (TU Delft) we see a growing diversity in students. We see the international student population growing, but also see significant differences in prior education, socio-emotional aspects, and competences. Within the Advanced Embodiment Design (AED) course, students work in teams on a client-based design project for a full semester. In 2018-2019, 22 student-teams started-out their endeavour, coached by eight coaches. On a weekly basis the coaches tracked the teams' performances by means of six key performance indicators. The weekly logs are aggregated, converted, and visualized in a performance dashboard which was used to lead the discussion on troublesome teams and solutions to get them back-on-track. In this cohort four operational problems were found: (i) cultural differences; (ii) differences in design approaches; (iii) emotional differences; and (iv) differences in student competences [1]. These typical problems were the result of our own coaches' perspective, and not so much from a student's perspective. To really get a grip on team dynamics and issues involved, we wanted to know what students come across when functioning in a multi-diverse design team. The goal of this research is to learn about the most occurring issues within multi-diverse teams and come to applicable solutions to help teams during the project, by building a 
framework to improve coaching of these teams within the context of this course. We started out exploring the literature surrounding the functioning of design teams and found different models describing the process. A well-known model of teamwork is the Tuckman model [2] of FormingStorming-Norming-Performing-Adjourning also addressed in Teamwork's [3]. The nature of this model is hierarchical where the following step can only be reached when the previous is accomplished. AED design teams have a more developmental dynamical nature where social processes and context often change. According to Miller [4] groups can be viewed as systems and in today's society and design challenges, personal and group related processes of creativity, introspection and intuition are more prominent [5]. Therefore, to frame team dynamics within the context of the AED course, and identify relevant issues and hurdles within multi-diverse teams we started out with the Lencioni's Pyramid [6,7]. The Lencioni pyramid model is based on his own experience as a business entrepreneur, where he distinguishes five levels for teams to function and excel. Although not scientifically backed up, it is a model embraced in team management. Teams build on trust (level 1), which makes them engage in healthy conflict (level 2), where clear goals help the team member to develop commitment (level 3). Peer to peer contact creates accountability (level 4) where finally team-members focus on the team results instead of personal gains (level 5).

The model of Lencioni has several similarities with the more science-based Theory $U$ developed by Scharmer [8]. Scharmer dives deeper into the reasons behind the functional 'presencing' teams and how to turn around dysfunctional 'absencing' teams. Both provide similar aspects in their framework for teams dealing with differences in competencies and design approaches. According to the Theory $U$ model for team development, all teams go through five stages when developing innovations. There are two opposing processes: (i) Presencing, where teams collaborate and embrace emerging possibilities, and (ii) Absencing, where teams disconnect and counteract in problem solving. Three elements are relevant for both processes and can be either open or closed. The 'mind' refers to the (non) judgement of team members based on prior experiences. The 'heart' refers to either emotional connecting or cynicism between team members. The 'will' involves the ability of teams to act in an instant. Scharmer also identifies a team working in the middle of the extremes where teams are neither present nor absent and just 'muddle through.' The model of Scharmer is a promising model to identify dysfunctional teams and will be used for future cohorts to track the team performance, identifying issues in team dynamics and turn around dysfunctionality.

The design teams consist of students with different preparatory schooling and often have different views on the design approach. Most teams also consist of a diverse group of nationalities which made us include this aspect in our research. In 'The Culture Map', Meyer [9] describes a model that defines eight key areas where cultures vary along a spectrum from one extreme to its opposite. The Culture Map provides a framework when student teams are dealing with cultural differences. By analysing the position of cultures relative to each other, team members are enabled to decode how culture influences their collaboration. The extremes on each scale are a continuum and within the range of behaviours of a given culture, individual differences will occur. The goal of the model is to support team members interacting with each other, to watch more, listen more and speak less.

As the goal of this paper is to build a framework to improve the coaching of multi-diverse student designteams, we explored whether the above frameworks work, and how they work, within the context of the course. Therefore, we researched the students' perspective on team-dynamics by evaluating the end-ofcourse reflections from our students of cohort 2018-2019.

\section{APPROACH}

The first step consisted of collecting students' data, which is useful to get an insight into the student perception and their issues when working in multi-diverse teams. We collected data from 117 master students following the master course Advanced Embodiment Design. Students work in teams of 4 to 6 people, on a client-based design project for a full semester in the period between February to July 2019. The student teams are supervised by teachers on a weekly basis. In addition to the content, the coaches coach mainly on group dynamics. The student teams run their own project within this 21EC course for a full semester. The students follow a complete process of embodying a product from prototype to nearproduction ripe product and have access to a physical studio to meet and collaborate on the project, simulating a real-life design studio experience. We asked our students to reflect on their work after delivering their course results. To get appropriate and consistent results we introduced our students to reflecting in week 16 of the semester, by means of a lecture to "become the best YOU", based on the 
'Reflective Practitioner' by Schon [10]. During this lecture students were exposed to three reflection methods they could use, ranging from low-level reflection using Symbols, to medium level reflection using the 'Kolb Learning Cycle' or deep reflection using 'Bateson Logical Levels' as described by Gordijn [11]. The covered methods guided the students while writing their reflections, but the deliverable was up to their own interpretation, which resulted in rich qualitative information. We received 61 essays, of which 54 students returned individual student reflections and 7 were reflected with their team. All student reflections were based in retrospect on the challenges experienced as an individual and as a team.

To analyse all reflection essays, qualitative coding was applied. This method served the most applicable to gain deeper insights from essay-long textual information [12]. These documents were imported into ATLAS.ti, a qualitative data analysis software for further processing. We used labels to index or categorize text in order to establish a framework of thematic ideas [13]. Using the built-in feature of ATLAS.ti, a word cloud was generated out of the most occurring words from the student reflections which inspired the process of further labelling. After an initial exploration of the first batch of documents, common themes were formulated from the student quotations. Expressions or full sentences were labelled with codes that occurred from the student quotations. Because quotations can be labelled with multiple codes that also enabled the researchers to explore connections between different code groups.

After finalizing all essays and clustering 308 unique quotations under 11 labels, we counted the number of occurrences for each label. This results in a list of priority issues and hurdles for our students when working in multi-diverse design teams.

\section{RESULTS}

All the students were asked to write an optional essay based on the proposed reflection methods. We introduced our students to three reflection methods and most students followed the Symbol approach. More than half of the students (61) running the course uploaded an essay on our education platform, of which 54 essays were written on a personal level and 7 were group based.

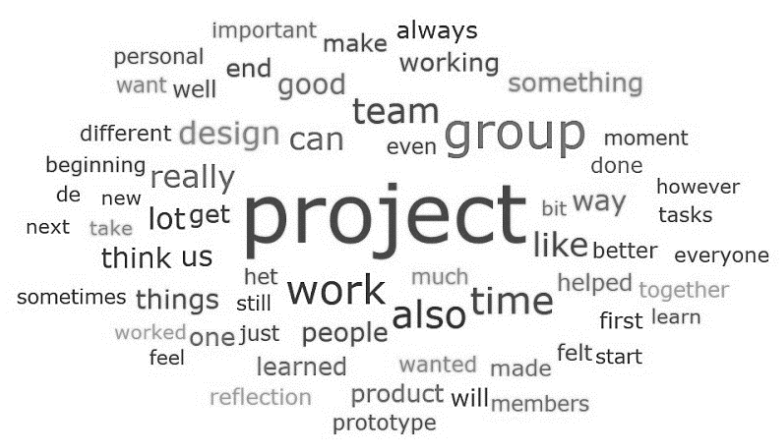

Figure 1. Word Cloud made from all reflection essays

From the student' reflection-essays we started out with a word cloud to find the most common terms and used this to inspire further labelling (figure 1). These words then served as input to systematically group the labelled quotations and categorize them based on the co-occurred themes. We identified 308 unique students' quotations, which were labelled and clustered into three main clusters and eleven associated subclusters:

1. Project Management, concerning issues with: Client Input; Progress Tracking; Coaching Influence; and Leadership Clarity.

2. Emotional Interaction, concerning issues with: Communicating Agreement; Managing Behaviour; Peer Feedback; Task-Related Concerns; and Cultural Differences.

3. Interdisciplinary, concerning issues with: Design Approach; and Previous Schooling.

Table 1 shows an overview of the main and subclusters together with the occurrences of these found subclusters in the students' reflection essays. It also gives example quotations taken from our students' essays to get an impression of issues concerned with the subclusters. 
Table 1. Overview of the main and subclusters, their occurrences and example quotations.

\begin{tabular}{|c|c|c|c|}
\hline Main cluster & Subcluster & Occurrences & Example quotation \\
\hline \multirow[t]{4}{*}{$\begin{array}{l}\text { Project } \\
\text { management }\end{array}$} & $\begin{array}{l}\text { Progress } \\
\text { tracking }\end{array}$ & 52 & $\begin{array}{l}\text { "Besides, the results of the sprints were sometimes } \\
\text { poorly documented causing trouble in later stages. } \\
\text { All this sometimes led to confusion and loss of } \\
\text { information." }\end{array}$ \\
\hline & Leadership & 31 & $\begin{array}{l}\text { "Because I like to keep a good overview of things, } \\
\text { I felt a bit lost due to this sometimes. This caused } \\
\text { me to lose a part of my sense of ownership over this } \\
\text { project." }\end{array}$ \\
\hline & Client input & 21 & $\begin{array}{l}\text { "We had very little contact with them, while they } \\
\text { could have steered us towards their desired } \\
\text { direction. However, it must be stated that the client } \\
\text { was very vague in what they wanted. They didn't } \\
\text { have a clear vision or scope themselves, making it } \\
\text { even harder for us." }\end{array}$ \\
\hline & $\begin{array}{l}\text { Coaching } \\
\text { influence }\end{array}$ & 19 & $\begin{array}{l}\text { "The coach was always on our side, trying to help } \\
\text { us solve the issues we had. Whenever he felt like } \\
\text { something was going wrong, he told us, and we } \\
\text { could change accordingly." }\end{array}$ \\
\hline \multirow[t]{5}{*}{$\begin{array}{l}\text { Emotional } \\
\text { interaction }\end{array}$} & $\begin{array}{l}\text { Communicati } \\
\text { on agreement }\end{array}$ & 39 & $\begin{array}{l}\text { "This led to parts of the project not always being in } \\
\text { sync with each other (e.g., things being interpreted } \\
\text { differently by different group members, leading to } \\
\text { conclusions/ parts of text that didn't fit together). I } \\
\text { think this was partly due to lack of communication } \\
\text { on some points." }\end{array}$ \\
\hline & $\begin{array}{l}\text { Managing } \\
\text { behaviour }\end{array}$ & 39 & $\begin{array}{l}\text { "I know that I am usually louder, so I try to make } \\
\text { sure to take a step back and also ask others for their } \\
\text { opinion if I feel that they are not being included." }\end{array}$ \\
\hline & $\begin{array}{l}\text { Task-related } \\
\text { concerns }\end{array}$ & 28 & $\begin{array}{l}\text { "I think we also lacked clear communication on } \\
\text { this point, mainly what everyone was working on, } \\
\text { how they were progressing and what else can be } \\
\text { done." }\end{array}$ \\
\hline & Peer feedback & 19 & $\begin{array}{l}\text { "it was brought to my attention that the team } \\
\text { noticed my drop in motivation towards the project. } \\
\text { I agree that my motivation for it was a little low, as } \\
\text { I felt like I was working on a dead end." }\end{array}$ \\
\hline & $\begin{array}{l}\text { Cultural } \\
\text { differences }\end{array}$ & 12 & $\begin{array}{l}\text { "I learned a lot about how to deal with different } \\
\text { people and different cultures. Everyone does things } \\
\text { in their own way and you need to find a way to } \\
\text { combine those ways of working." }\end{array}$ \\
\hline \multirow[t]{2}{*}{$\begin{array}{l}\text { Inter- } \\
\text { disciplinary }\end{array}$} & $\begin{array}{l}\text { Previous } \\
\text { schooling }\end{array}$ & 27 & $\begin{array}{l}\text { "I also learned to work in a multidisciplinary team } \\
\text { where everybody has a different skill set. Although } \\
\text { most people mostly did what they were } \\
\text { comfortably with and good at, we also took each } \\
\text { other along and taught each other the needed } \\
\text { competences." }\end{array}$ \\
\hline & $\begin{array}{l}\text { Design } \\
\text { approach }\end{array}$ & 21 & $\begin{array}{l}\text { "What I didn't agree with was how emphasis was } \\
\text { put on certain things, while other things that I } \\
\text { thought were more important were neglected." }\end{array}$ \\
\hline
\end{tabular}

A relationship graph was made by adding co-occurring cluster codes (figure 2). The clustered data revealed interesting results in terms of subclusters as well as their relationships with each other. In terms of Project Management, Progress Tracking proved to be the most challenging (22.7\%) for students, while for Emotional Interaction both Communicating Agreement as well as Managing Behaviour takes 
up $17.0 \%$ of the quotations each. Within Interdisciplinarity previous schooling (11.8\%) within the project team seems to be an aspect to consider.

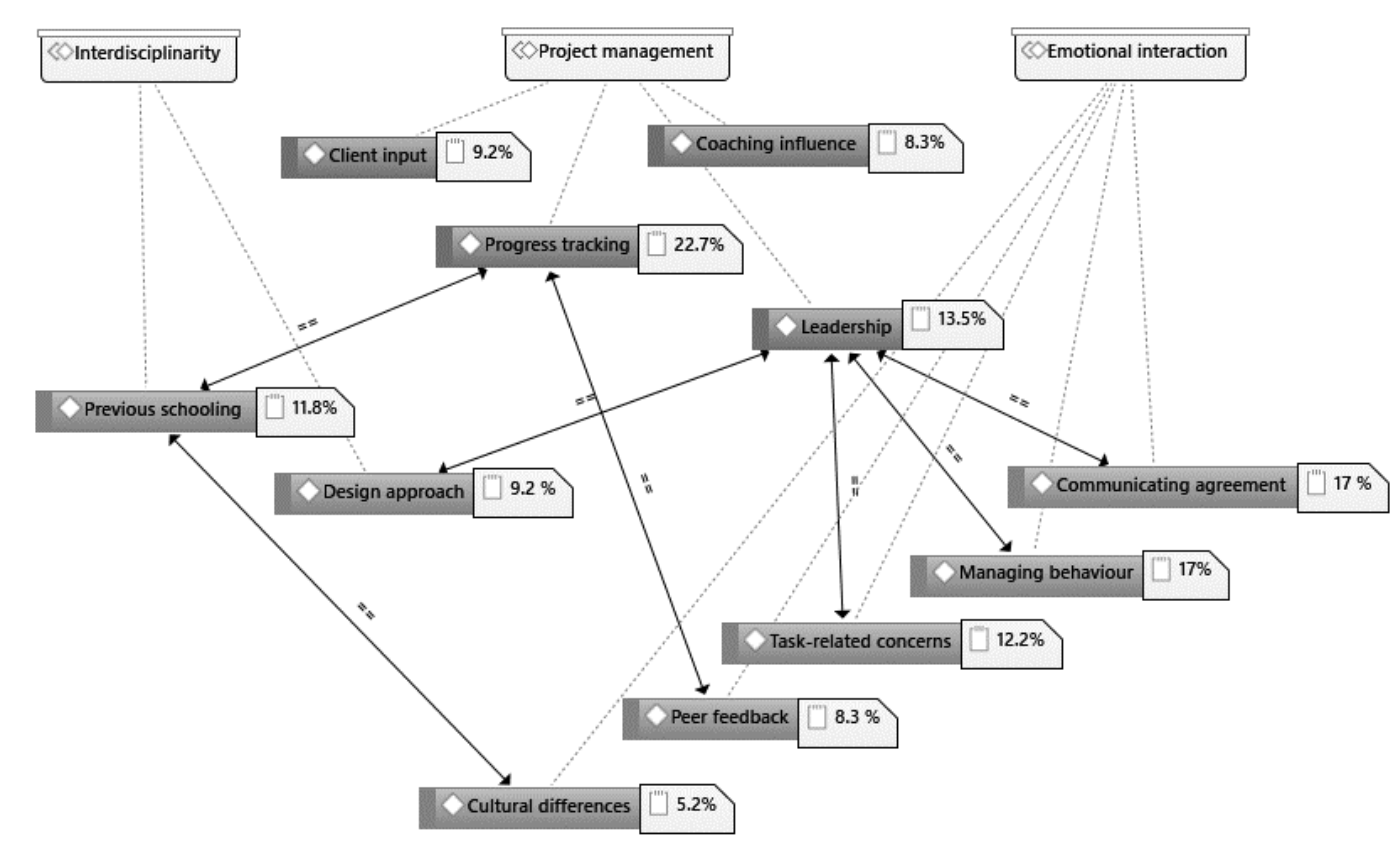

Figure 2. The relationship graph of all students' quotations clustered in three main clusters consisting of eleven subclusters

Starting the network with the main clusters, typically three or four subclusters are associated with each other by being mentioned in the same quotations. For example, the ability to be efficient in Progress tracking was associated with Previous Schooling which in its term was also related to Cultural Differences. The labelled data revealed that Progress Tracking is closely related to giving feedback among peers and previous schooling. Visualizing the associations between the subclusters shows that lack of clear consensus on leadership within the design team causes challenges from various aspects, e.g., leading to difficulties in role agreements, task concerns and design approaches, as well as managing individual behaviours.

Despite initial assumptions, Cultural Differences led to the smallest number of challenges (only 5.2\% of the quotations referred to these challenges) but scored high in terms of relations to other clusters. In comparison, Client Input also has a smaller number of related quotations $(9.2 \%)$ but also did not prove to be associated with other clustered challenges, and thus is of lesser importance.

\section{CONCLUSIONS \& DISCUSSIONS}

In this paper we have discussed the students' perspective on team-dynamics and the issues they come across. In our previous research [1] we identified the key issues concerning four types of diversity (cultural, design approach, emotional and competencies). In the current paper we have researched the student perspective on issues when working in multi-diverse design teams. By qualitative coding of 61 reflection essays, we identified 11 subclusters of issues, where three subclusters were identified as the most troublesome to student teams: Progress tracking, Communication agreement and Managing behaviour. In general, this means that the coaches need to pay attention to the following aspects while coaching the student design teams: (i) project planning and tracking their progress during the run; (ii) finding a way to communicate with each other on task level but also on trust level; which is closely related to (iii) the last issue where students need to manage their own behaviour, sensing each other better. The Theory- $U$ seems to work very nicely in tracking these aspects in the process of a group of students becoming effective design teams.

Despite initial assumptions, Cultural Differences were indicated as the least challenging part of working in a design team, where only $5.2 \%$ of the quotations referred to these challenges. This can be caused by the often-low-level reflections in the written essays but can also be caused by ethical issues where 
students will not mention cultural indifferences in an official document. Several key-areas as discussed by Meyer, like communication and leadership, are key issues in groups of students becoming effective design teams. When communication is bad, and leadership is low, students tend to either be absent or 'muddle through,' as described by the Theory U [8]. Therefore, we expect that cultural differences are an underlying aspect of the three main subclusters and will keep this in focus when coaching design teams.

The final deliverable for a team consists of an embodied design of a product. However, the major learning is not in designing the product, but in working together and inclusively in the multi-diverse design-team. The experience of differences between team members and learning to trust each other is the basis of a functional team. To support our students in a safe way during this process, we need to professionalize our coach team and focus more on team dynamics, getting in flow with the project team, and experiencing a higher level of collaboration.

In the upcoming years we will increase the knowledge and skills of our coach team on topics like Dialogue and Theory $\mathrm{U}$, to help our student groups in their process of becoming highly effective teams. To be on top of the students' performance, and indicate when student teams are running off-track, we are further developing our KPI based tracking system. To increase the reliability of the reflection data, we will improve the quality of the students' reflection essays.

This research has received funding from the Comenius Teaching Fellowship funded by the NRO in the Netherlands.

\section{REFERENCES}

[1] Flipsen B. and Persaud S. M. Handle with care: coaching multi-diverse project groups to become healthy design teams, E\&PDE 2020, University college, Herning, Denmark, 2020.

[2] Tuckman B. W. and Jensen M. A. C. Stages of small-group development revisited. Group Organization Management, 2(4), 1977, 419-427.

[3] Smulders F., Brehmer M., and Meer van der H. (2012), Teamwork's, by students, for students. Mozaic Business Publishers, Delft, 2012

[4] Miller D. L. The Stages of Group Development: A Retrospective Study of Dynamic Team Processes, Canadian Journal of Administrative Science, 20(2), 2003, pp. 121-134.

[5] Senge P. Scharmer O., Jaworski J., and Flowers B. S. Presence: Human purpose in the field of the future. Cambridge, MA: The Society for Organizational Learning, 2004.

[6] Lencioni P. The Five Dysfunctions of a Team, Jossey-Bass, 2002.

[7] Lencioni P. Overcoming The Five Dysfunctions of a Team, Jossey-Bass, 2005.

[8] Scharmer O. Theory U, Leading from the Future as it Emerges, Berett-Koehler Publishers, 2016.

[9] Meyer E. The Culture Map, Public Affairs, New York, 2014.

[10] Schon D. A. The Reflective Practitioner: how professionals think in action, Aldershot: Ashgate Publishing Ltd., 1991.

[11] Gordijn F., Eernstman N., Helder J. and Brouwer H. Reflection Methods, Wageningen Centre for Development Innovation, Wageningen University \& Research, 2018.

[12] Castleberry A. N., Payakachat N., Ashby S., Nolen A., Carle M., Neill K. K., and Franks A. M. Qualitative Analysis of Written Reflections during a Teaching Certificate Program. American journal of pharmaceutical education, 80(1), 10, 2016

[13] Gibbs G. R., Thematic coding and categorizing. In Analysing qualitative data, SAGE Publications, Ltd., 2007, pp. 38-55. 